THE LIGHT AT THE END OF THE TUNNEL : THE IMPACT OF POLICY ON THE GLOBAL DIFFUSION OF FLUORESCENT LAMPS

Suchita SRINIVASAN 


\title{
The Light at the End of the Tunnel: The Impact of Policy on the Global Diffusion of Fluorescent Lamps
}

\author{
Suchita Srinivasan
}

This version: July 2016

\begin{abstract}
The objective of this paper is to evaluate the effectiveness of different policies in facilitating the diffusion of green innovations through trade. Focusing on developing countries, this paper develop analyses the effectiveness of policies such as information, subsidies, and banning the use of the incumbent technology in encouraging the use of a clean technology. The empirical model uses a novel dataset of a sample of 72 low and middle-income countries, spanning the period 1993- 2013 to evaluate the effectiveness of these policies, and analyse the determinants of policy choice. Results suggest that domestic policies pay a pivotal role in facilitating the transfer of CFL, especially subsidies; however, simultaneous implementation of policies need not necessarily be effective. Moreover, countries learn from the experiences of other countries in deciding whether to implement a particular policy. Results also suggest a role for trade policy instruments, such as trade agreements with top exporters, to facilitate clean technology diffusion.
\end{abstract}

Keywords: Technology Diffusion; Policy Effectiveness; International Trade.

JEL Codes: D78;D83;F13;H30;O33;O38;Q48.

\footnotetext{
*Department of International Economics, Graduate Institute of International and Development Studies, Geneva, Switzerland, and Centre for International Environmental Studies, Geneva, Switzerland. e-mail: suchita.srinivasan@graduateinstitute.ch.I would like to thank Liliana Andonova, Francois Cohen, Joy Kim, Bruno Lanz, Joelle Noailly, Mare Sarr, Timothy Swanson and participants at the EAERE meeting in Helsinki, the Sinergia Conference on Innovation and Green Growth in London and the SNIS Workshop in Geneva for useful comments and discussions. Funding from the Swiss Network For International Studies (SNIS) is gratefully acknowledged.
} 


\section{Executive summary}

Identifying the barriers to the diffusion of low-cost clean technologies is imperative, not just in evaluating the effectiveness of different policy measures in dismantling them, but also for ensuring their faster dissemination. This is especially crucial for developing countries, where many related factors may inhibit the adoption of clean technologies by consumers, such as lack of affordability, access, information, or behavioural characteristics that hinder households from switching to cleaner alternatives to existing technologies.

Energy-efficient lighting is an example of a cost-effective clean technology, which has still not been adopted on a large scale, despite several measures taken by governments, electricity utilities and manufacturers to increase their adoption. One of the main reasons for slow uptake is the higher relative prices of energy-efficient lamps such as compact fluorescent lamps (CFL) compared to the incumbent technology, namely incandescent bulbs (IB). Additional reasons are a lack of information amongst consumers about the characteristics of these technologies, initial quality related concerns, and specific consumer preferences for features (such as the colour of light).

The objective of this paper is to evaluate the effectiveness of policies implemented by governments in encouraging the diffusion of CFL (compact fluorescent lamps) into developing countries that do not produce these lamps on a large scale. The policies that are evaluated are information policies (such as labelling schemes and awareness campaigns), price incentives (such as subsidies and free CFL distribution schemes), and a ban on the import (or sale) of IB in facilitating imports of these lamps. The paper develops a novel dataset using information from the United Nations Environment Programme (UNEP) En.lighten Initiative country policy map on 72 countries from 1993 to 2013 for the analysis.

The methodology adopted in the paper is the instrumental variable two-stage least squares (IV2SLS) model in order to study policy choice by governments in this sample of countries, and study their effectiveness in increasing the adoption of CFL (measured by imports of these bulbs relative to total imports of CFL and IB). In addition, the paper also tries to understand whether multiple policies, implemented simultaneously, are complementary in increasing effectiveness and whether countries learn from the experiences of other countries in deciding which policies to implement.

Results suggest that each of the three policy options considered is effective in ensuring greater CFL adoption in this sample of countries, with subsidies being the most effective suggesting that 
cost-related factors are the main hindrance towards greater adoption of these lamps. In addition, both the effectiveness of these policies when implemented, and the choice of a policymaker to implement them, depends strongly on how effectively the policymaker can implement these policies and on what scale.

The paper also provides evidence to suggest that countries learn from the experiences of other countries when deciding about which policies to implement. This is particularly encouraging, especially for the lighting industry, because several initiatives initiated to provide information to consumers and subsidise CFL, were implemented at a regional level such as the ECOWAS, the Lighting Africa initiatives in Africa and the UNEP En.lighten Initiative in the Middle-East, Asia, Sub-Saharan Africa and Latin America.

Lastly, the paper finds that the diffusion of this technology (through imports) can be facilitated by trade agreements between countries and exporters of CFL and favourable relative tariffs between the two technologies under consideration. This has relevant policy implications, especially for technologies that are primarily imported by developing countries, in the absence of domestic production capacities.

There are certain limitations to the results of this paper. Firstly, it does not provide a normative evaluation of the policies implemented due to the absence of data needed in order to draw such inferences (such as the cost of implementation of these policies in developing countries, the time needed to actually implement them, etc.). Secondly, the analysis is unable to identify the scale on which policies are implemented, and thus treats all policies as equivalent in terms of size.

This paper finds broad applicability with implications for the implementation of policies to encourage clean technology transfer in developing countries. While the ultimate choice of policy depends both on effectiveness and welfare implications (including the cost of implementation of these policies), this paper provides some initial evidence on which kinds of policies are effective and on what kind of factors policy makers base their decisions. Additionally, given that domestic production capabilities are often either absent or limited in scale in developing countries, this paper provides evidence on trade-policy instruments, which can be used additionally to facilitate technology-transfer via imports. These findings are useful both in identifying the nature of barriers to clean technology diffusion and suggesting possible remedies for it. 


\section{Introduction}

It is widely accepted that policymakers should formulate climate-change mitigation strategies that incorporate multiple policy instruments (or one per market failure) for reducing greenhouse gas emissions to meet global obligations (such as those mandated by the Kyoto Protocol). An important source for achieving these reductions in emissions is improving the energy efficiency of electrical appliances that are used by households, which may not only reduce energy consumption but can also achieve cost-savings for households.

Energy-efficient lighting is an example of an area where significant opportunity for these reductions lies. In 2005, lighting accounted for 2650 terawatt-hours, or approximately 19 per cent of global electricity use per annum: it was also responsible for eight per cent of global $\mathrm{CO}_{2}$ emissions, which is equivalent to about 70 per cent of total emissions from all passenger vehicles in the world (Lefèvre et al., 2006). As the population burgeons in the developing world, carbon-dioxide emissions can be expected to increase. Improving the energy efficiency in lighting is thus an important (and arguably, relatively simple) way to reduce energy use, at least in the short run.

The objective of this paper is to evaluate the effectiveness of policies implemented by governments in encouraging the diffusion of a clean lighting technology, the compact fluorescent lamp (CFL), into developing countries that are not large producers of these bulbs. The analysis focuses on the role of information policies (such as labelling schemes and awareness campaigns), price incentives (such as subsidies and free CFL distribution schemes), and a ban on the import (or sale) of incandescent lamps (IB) in facilitating imports of these lamps. The paper conducts an empirical estimation using data from 72 low and middle income countries from 1993 to 2013.

There have been several improvements in lighting technologies in recent times. The traditional lighting technology has been the IB. ${ }^{1}$. Energy-efficient CFL have potential to generate residential energy savings, on average consuming $20-25$ per cent of the energy used by IB, for providing the same amount of light (Lefèvre et al., 2006). The life span of a CFL is much higher than that of an IB: the average IB has a life of about 1000 hours, compared to 5000-25000 hours for the CFL

\footnotetext{
1 .An IB: "produces light when an electric current passes through a filament and causes it to glow", whereas a CFL "produces light when an electric arc passes between cathodes to excite mercury and other gases producing radiant energy, which is then converted to visible light by a phosphor coating" (ALA, 2199)
} 
(Lefèvre et al., 2006). ${ }^{2}$

Despite several benefits of using CFLs, their uptake has been limited. CFLs only accounted for about 6 per cent of the world lighting market in 2006 (Lefèvre et al., 2006). A significant hurdle has been the high initial cost of these bulbs compared to IBs. However, it appears that a lack of affordability is not the only factor dissuading consumers: Allcott and Taubinsky (2015) provide evidence from two randomised control trials conducted in the US, that aim to provide consumers with information about the energy costs of different light bulbs. They find that CFLs and IBs are imperfect substitutes. Their key results are that while consumers benefit from subsidies and minimum energy performance standards, these are only second-best policies. They find effective information dissemination to remain the most potent policy, given that uncertainty about the lamp life is a significant deterrent towards their greater adoption.

There is already a broad theoretical literature that looks at the role of policy instruments in incentivising firms to switch to using cleaner technologies: Jaffe and Stavins (1994) build a theoretical model to understand the "energy paradox" or the limited adoption of energy-saving technologies by firms. They attribute the slowness of clean technology diffusion to information asymmetries, private information costs, high discount rates and heterogeneity among potential adopters. In this paper, some of these factors (in particular private costs and lack of information) are found to be important deterrents for greater CFL adoption amongst consumers as well. Requate and Unold (2003) find that for an individual firm, it is not immediately clear that price instruments are more effective than command-and-control policies in the adoption of abatement technologies and that the relative superiority of different policy instruments depends on whether regulators are able to anticipate the development of new technologies. In this paper, the policies are ranked based on effectiveness and it finds that for consumers in developing countries, price instruments are most effective.

In the empirical model developed in this paper, the objective is to study the effectiveness of different policy instruments both when implemented in isolation and in conjunction with other policies. An instrumental variable two-stage least squares (IV-2SLS) estimation is used, where the endogenous policy variables are dummy variables which indicate the presence of a policy in a

\footnotetext{
2 .The current technology frontier though is represented by the light-emitting diodes (LEDs), which are even more energy-efficient than CFLs.
} 
given country, in a given year. The measure of diffusion used in this paper is the quantity of CFL imports, as the countries in the sample are not major producers of these bulbs. The use of imports as a measure of CFL diffusion yields the familiar S-shaped diffusion curve, which is a common finding in the empirical literature. ${ }^{3}$

The empirical literature on the role of policy instruments in encouraging technology diffusion is very broad and comprises both cross-country analyses and country-specific studies.Comin and Hobijn (2004) introduce a novel historical cross-country dataset to study the diffusion of various technologies. They find that these technologies are first adopted by advanced economies and subsequently by relatively less developed countries. Moreover, they find that it may take a long time for a new technology to start dominating its predecessor. These findings support the general observations that CFL use lags behind in developing countries (compared to that in developed countries), and that consumers have been reluctant to switch from IB to CFL. Johnstone et al. (2010) look at the effect of environmental policies on innovation across countries in five different renewable energy technologies, using patent applications as a proxy for innovative activity. This paper is akin to Johnstone et al. (2010) in capturing the effect of (heterogenous) policies.Bosetti and Verdolini (2013) also use policy dummies to look at the diffusion of both renewable and fossilfuel based technology in the power sector. They use a dynamic panel to test the effectiveness of different policies, in order to deal with possible endogeneity of these variables.

Comin et al. (2012) find a role for distance from adoption leaders in explaining the slow adoption of technologies. However, they also find that the effect of distance diminishes over time and eventually disappears. In this paper, the spatial differences in policy adoption (rather than in the adoption of the CFL technology itself) are utilised in constructing the instrumental variable for the (endogenous) policy variables that are used in the IV-2SLS estimation. This is built on the assumption that distance to (policy) adoption leaders matters and that countries "learn" from the experiences of other, close countries in deciding which policies to implement.

This approach has been adopted in the literature: Guasch et al. (2003), for instance, use the presence of contractual clauses in other countries to instrument for the presence of a contractual clause in a certain country and its consequent impact on rates of contract renegotiation in the

\footnotetext{
3 .Griliches (1957), Mansfield (1961) and Mansfield (1968) were some of the first papers which studied the diffusion patterns of hybrid corn in the US, and of several industrial innovations respectively, and derived the "logistic curve" synonymous with diffusion.
} 
infrastructure sector in Latin American countries. This is also found in the literature on spatial spillovers in fiscal policy choices: Keen and Lockwood (2010) used the assumption that the adoption of value-added tax in a country depends on its adoption in neighbouring countries. Ebeke and Ngouana (2015) propose the use of energy subsidies in neighbouring countries as an instrument for energy subsidies in a sample of low-income countries.

Reppelin-Hill (1999) posited that the trade openness of an economy might play a role in the global diffusion of electric-arc furnaces in the steel industry. She finds that these technologies are adopted faster in countries with more open economies. This paper uses a more specific measure of whether a country is open to trade in CFL (namely whether the country has entered into a trade agreement with a top exporter of CFL in a given year) and finds that it is also a determinant of diffusion.

This paper suggests that the choice of policy may be driven by the scale of project implementation, i.e. the resources available with the government, and its capacity for enacting these policies. The empirical model developed examines whether these factors might determine whether one of the three policies discussed is chosen or not.

This paper also studies possible complementarities between policies. There are other countrylevel studies that look at the role of different policies in encouraging new technology adoption and also examine their complementarity, especially in health economics. Ashraf et al. (2013) conduct a field experiment in Zambia encouraging households to buy a health product and find that information policies and subsidies are complementary to each other, i.e. informing the public) renders subsidies effective in encouraging the purchase of these products. However, there has been no study that considers the complementarity of different policies in encouraging clean technology adoption.

The main findings of this paper are that each of the policy options considered within it are effective in ensuring greater CFL adoption in this sample of countries, with subsidies having the greatest impact. Moreover, the impact of these policies may depend on how effectively the policymaker can implement these policies and on what scale. The paper also provides evidence to suggest that countries mimic the behaviour of their neighbours in adopting clean technologies, and that trade agreements between countries and exporters of CFL could play an important role in its greater diffusion. 
This paper makes three main contributions to the literature on the impact of policy on clean technology diffusion: the first is its focus on low and middle-income countries. Given that this is a sample of countries where opportunities for cheap emissions-abatement lie, it is critical to understand which policies are effective in lower-income countries. Most of the current literature on the impact of policy on clean technology adoption uses data from experiments (or surveys) implemented in developed countries. ${ }^{4}$ This is the first paper to use data from a cross-section of developing countries.

The second main contribution of this paper lies in the creation and use of a novel data set to evaluate the usefulness of different policy options in encouraging the diffusion of CFL. The presence or absence of these policies has been coded using information provided in the United Nations Environment Programme (UNEP) En.Lighten Initiative country policy map (UNEP, 2014), which provides extensive information on the current status of clean lighting adoption in several countries, along with a list of the policies that have been adopted to encourage greater use of CFL.

The final contribution of this paper lies in its findings about possible complementarity of these policies when implemented together, and thus a possible implication on the sequencing of policies in developing countries to ensure clean technology adoption. To my knowledge, this is the first paper to draw on the complementarity of policy instruments in encouraging clean technology diffusion.

The structure of the paper is as follows: section 3 explains the data and methodology used for the empirical analysis and also includes the empirical results: section 4 provides the policy implications, and section 5 sets out the conclusion.

\section{Data, methodology and results}

\subsection{Data}

In the empirical model developed in the next two subsections, cross-country data is used to study the effectiveness of three policy instruments: information provision schemes, subsidies and the ban on the use of IB, as well as looking at the determinants of this policy choice. The panel data focuses

\footnotetext{
4 .Allcott and Taubinsky (2015) use data from two randomised control trials in the US, while Mills and Schleich (2010) look at the barriers to a household looking to adopt CFL, using German survey data.
} 
on lighting industry-specific policy adoption in a sample that includes 72 low and middle income countries, and spans 1993 to 2013. Table 6 (in the Appendix) presents the countries that are included in the data sample. The sample comprises six main geographic regions: the Middle-East, Caribbean/Latin America, Central Europe, South Asia, East Asia and Sub-Saharan Africa.

The countries included in the sample were chosen on the basis of the availability of data on policies adopted and whether they were categorised as low-income, lower middle-income or upper middle-income, according to the World Bank 2014 classification. Due to concerns of sampleselection bias arising due to inclusion of only countries that imposed some policies, those countries were also included that have not enforced any policies.

The measure of diffusion used in the empirical estimation is the (logarithm of) imports of CFL as a proportion of total imports of IB and CFL, measured in terms of weight (in tons). The paper follows the literature (Caselli and Coleman, 2001) in using imports as a measure of diffusion. Caselli and Coleman (2001) use computer imports per worker as a measure of the cross- country diffusion of technology, and justify its use on the grounds that the computer industry is concentrated, with only a few countries providing most of the world's computer output. Technology diffusion in this case takes place through imports of the equipment embodying the technology. This argument is valid in this paper as well: the countries included in the data sample are not major producers of CFL, which implies that quantity of imports is a reasonable measure of their level of diffusion of CFL. Papageorgiou et al. (2007) also use real imports of medical equipment per capita as a measure of international medical technology diffusion. Another reason for the use of imports as a measure of diffusion is that it is difficult, if not impossible, to find data on consumption of lamps in the low and middle income countries included in the sample. Data on trade in lamps is obtained at the Harmonised System six-digit level of classification from the UN COMTRADE database (UN, 2014).

Some of the bigger developing countries, which export CFL are excluded from the sample, most notably China, which has accounted for almost 60-70 per cent of exports of CFL in recent years. Other exporters such as Hungary, Indonesia and Thailand are also excluded. This is done to omit countries with large production capabilities. Additionally, observations for which the ratio of value of imports to exports is less than one are also dropped from the analysis.

The main independent variables of the model are the policy dummies, which are dummy vari- 
ables to indicate the presence of a lighting- specific policy in the country (in particular, CFL). These have been manually coded using information provided by UNEP and from individual reports from countries' electric utilities, governments, etc. These dummy variables are created to indicate the presence of voluntary/mandatory labels and awareness campaigns (i.e. the information provision policy of the government), price incentives such as subsidies, loans, tax rebates, and schemes for the free distribution of CFL and a ban on the use or import of IB. These policy variables take the value one in a certain period, if the policy is implemented in the same period, and zero otherwise.

These policies are the main instruments used by policymakers in developing countries to encourage consumers to switch to CFL. The only notable exception is the imposition of minimum energy performance standards. While information on the use of these standards was also available in the UNEP database, this variable was found to be highly correlated with the dummy for information provision, and thus it has not been used in the empirical estimations ${ }^{5}$. This is because most energy labels printed on appliances such as light bulbs are required to display the energy performance standards that the product meets, which are often certified by local authorities.

Since the measure of diffusion used is imports of lamps, it is imperative to control for measures of trade policy in the empirical estimations. For instance, a trade agreement indicator is used for estimation, which takes the value one if the country is in a trade agreement with one of the top five exporting countries of CFL in a given year (De Sousa, 2012), and zero otherwise. A variable for the ratio of tariffs on CFL to tariffs on IB (in the previous time period) is also included (WB, 2014).

Other variables used include an indicator for government effectiveness in policy formulation and implementation (taking the value one if the government is "effective", zero otherwise). The government effectiveness indicator is created using the Government Effectiveness Index data from the World Governance Indicators Database. This index: "reflects perceptions of the quality of public services, the quality of the civil service and the degree of its independence from political pressures, the quality of policy formulation and implementation and the credibility of the government's commitment to such policies" (WB, 2012). Additionally, in order to derive a measure of income that is more suited to the lighting industry, the "Sum-of-Lights" variable is used, which is created using night-time satellite data, to proxy for the level of development of an economy (NOAA, 2014).

\footnotetext{
5 .The pairwise correlation coefficient was found to be 51 per cent
} 
Table 1 below presents the descriptive statistics of the variables. As can be seen, the most popular policy measure is information provision, while very few countries in the sample have enforced a ban on IB.

Table 1: Summary Statistics of Independent Variables

\begin{tabular}{lcccccc}
\hline \hline Variable & Obs. & Mean & Std. Dev. & Min. & Max. & Missing \\
\hline Information Provision(\%) & 1454 & 0.225 & 0.418 & 0 & 1 & 0 \\
Subsidy(\%) & 1454 & 0.195 & 0.396 & 0 & 1 & 0 \\
Ban on IB (\%) & 1454 & 0.049 & 0.216 & 0 & 1 & 0 \\
Information IV (Distance-weighted \%) & 1376 & 1618.393 & 2203.139 & 0 & 13178 & 78 \\
Subsidy IV (Distance-weighted \%) & 1348 & 1640.106 & 2124.016 & 0 & 12198 & 106 \\
Ban IV (Distance-weighted \%) & 1400 & 387.857 & 1047.625 & 0 & 9030 & 54 \\
Trade Agreement Indicator (\%) & 1454 & 0.146 & 0.354 & 0 & 1 & 0 \\
Ratio of Tariffs (in period t-1) & 691 & 0.900 & 0.480 & 0 & 5 & 763 \\
Govt. Effectiveness Index & 969 & 0.209 & 0.407 & 0 & 1 & 485 \\
"Sum-of-Lights" Index & 1382 & 520766.1 & 1238273 & 592 & 19000000 & 72 \\
\hline
\end{tabular}

Figure 1 (in the Appendix) shows the policies (and their combinations) that have been adopted by countries in the data sample: it is clear that in most countries, the combination of information provision policies and subsidies is the most popular policy choice. Additionally, no country implements the ban in isolation. Information policies are relatively-well spread out amongst the countries in the sample, fewer countries have adopted price incentives to get consumers to switch from IB to CFL, and even fewer have imposed a ban on IB (this is also apparent from Figure 2, which plots the evolution of adoption rates for these three policies over time across the sample). As is clear from this graph, information policies have always been the most prevalent form of policy intervention undertaken by governments, whereas the ban has become increasingly popular since 2006/07. Figures 3 and 4 plot the share of imports and exports of CFL over time in the sample. It is clear that the share of imports of CFL has increased over time, pointing to the possibility of greater diffusion of these lamps. The increase in the share of CFL exports over time suggests that some of these countries may have become producers of CFL. However, these countries' exports are still not significantly large enough in terms of value to merit their inclusion in the sample. 


\subsection{Methodology and results}

The objective of the empirical estimation is to explain how various policies affect the share of CFL that a country imports. The model that is estimated is as follows:

$$
M_{i t}=\alpha_{0}+\alpha_{1} D_{i t}+\alpha_{2} X_{i t}+\mu_{i t}
$$

where $M_{i t}$ denotes the share of imports of CFL in country i at time t (over total imports of CFL and IB in country $\mathrm{i}$ at year $\mathrm{t}$ ), $D_{i t}$ denotes country- specific policy dummies at time $\mathrm{t}$, and $X_{i t}$ denotes country-specific controls in time t. $\mu_{i t}$ denotes the stochastic error term. The linearprobability model is used for this estimation. There are two reasons for not converting the dependent variable to a dummy variable (and using logit or probit for estimation): firstly, many countries implemented the policies for one year only, i.e. there are "observation-specific" dummy variables as regressors (especially subsidies, and the ban on IB). Anderson (1987) has shown that neither logit nor probit can be used to estimate the coefficients on observation-specific dummy variables. Additionally, Angrist and Pischke (2008) point out that if the intention is to obtain marginal effects, the difference between non-linear methods (such as logit and probit), and the linear approach adopted in this paper, is not too significant.

From the onset, it is clear that there are serious endogeneity concerns in estimating model 1: it is entirely possible that policymakers implement new policies after observing the share of imports of CFL, a risk which cannot be entirely eliminated by using lagged policy dummies, for instance. This would mean that $D_{i t}$ in (1) is endogenous. Possible existence of such reverse causality implies that OLS estimates will be inconsistent: to deal with this endogeneity concern, the model used for estimation of (1) is the instrumental variable model, using the two-stage least squares method of estimation.

The baseline results of the paper only study the effects of the policies, considering them one at a time. The main reason for adopting this approach is to avoid difficulties with interpretation of coefficients with multiple endogenous variables. The first-stage robustness checks are also more tedious (Angrist and Pischke, 2008)). ${ }^{6}$

\footnotetext{
6 .However, certain estimations require the use of multiple endogenous variables: for instance, in order to test for the strength of the interaction between the presence of the policies government effectiveness, both the main effect (the policy dummy) and the interaction term are treated as endogenous.
} 
The instruments used for the policy dummies are constructed as weighted averages of the presence of the same policy in one of the five nearest countries to the one in question, where the weight represents the distance of the country from the neighbouring country. Data on distances are taken from the Geodist Database ((Mayer and Zignago, 2011)). There is evidence to suggest that countries in a common geographical region learn from the experiences of other countries in deciding which policies to implement ((Guasch et al. (2003), Keen and Lockwood (2010), Ebeke and Ngouana (2015)). Given that energy-efficiency related policies are often implemented as regional initiatives, often in collaboration with international organisations (examples include the ECOWAS and Lighting Africa initiatives in Africa, and the UNEP En.lighten initiative in the MiddleEast, Asia, Sub-Saharan Africa and Latin America), it is very likely that countries do learn from each other in implementing policies. However, it is important to keep in mind the direction of learning: it is probable that Nepal learns from the experiences of India in implementing a policy, but the converse is not likely, given that India was one the first countries in South Asia to implement lighting policies. To account for such possibilities, the instrument is a weighted average of the presence of a policy in the five nearest countries to the given country either in period $t$, in period $\mathrm{t}-1$, or in period $\mathrm{t}+1$. This ensures that both "follower" countries (countries mimicking policy implementation) and "lead" countries (countries pioneering policy implementation) are accounted for: follower countries can implement the policy implemented by the lead country either in the same time period, or in the next.

It is empirically difficult, if not impossible, to verify whether the exclusion restrictions are satisfied in this case: the Sargan-Hansen test of over-identifying restrictions can be used if there are more instruments than included endogenous variables. However, it is difficult to identify another channel through which adoption of policies in neighbouring countries may affect the share of imports of CFL in a country, other than through its influence on a country's decision to adopt the same policies. The import share of CFL should not depend on the policies enforced in other countries, provided none of these countries are themselves large producers, and no country imports an unusually large quantity of CFL.

The baseline empirical results are provided in Table 2 below, which presents the second-stage 
Table 2: IV-2SLS Results (Second-Stage Estimation)

\begin{tabular}{|c|c|c|c|c|c|c|}
\hline & (1) & (2) & (3) & (4) & (5) & (6) \\
\hline Information & $\begin{array}{l}1.072 * * \\
(0.487)\end{array}$ & $\begin{array}{c}3.632 \\
(9.545)\end{array}$ & - & - & - & - \\
\hline Subsidies & - & - & $\begin{array}{l}1.996 * * \\
(0.813)\end{array}$ & $\begin{array}{c}-2.418 \\
(9.828)\end{array}$ & - & - \\
\hline Ban on IB & - & - & - & - & $\begin{array}{l}1.505 * * \\
(0.712)\end{array}$ & $\begin{array}{c}0.284 \\
(1.832)\end{array}$ \\
\hline Trade Agreement Indicator & $\begin{array}{c}0.103 \\
(0.194)\end{array}$ & $\begin{array}{c}0.054 \\
(0.301)\end{array}$ & $\begin{array}{c}0.276 \\
(0.226)\end{array}$ & $\begin{array}{c}-0.346 \\
(1.755)\end{array}$ & $\begin{array}{l}0.349 * * \\
(0.141)\end{array}$ & $\begin{array}{c}0.098 \\
(0.281)\end{array}$ \\
\hline Ratio of Tariffs (in period $\mathrm{t}-1$ ) & $\begin{array}{c}-0.607 * * * \\
(0.221)\end{array}$ & $\begin{array}{c}-0.341 \\
(0.978)\end{array}$ & $\begin{array}{c}-0.502^{* *} \\
(0.252)\end{array}$ & $\begin{array}{c}-0.815 \\
(0.649)\end{array}$ & $\begin{array}{c}-0.797 * * * \\
(0.180)\end{array}$ & $\begin{array}{r}-0.684 * * \\
(0.214)\end{array}$ \\
\hline "Sum-of-Lights" Index & $\begin{array}{l}-1.680 * \\
(0.962)\end{array}$ & $\begin{array}{c}-1.250 \\
(2.950)\end{array}$ & $\begin{array}{c}-4.710 * * \\
(2.340)\end{array}$ & $\begin{array}{c}0.091 \\
(8.230)\end{array}$ & $\begin{array}{c}-2.040 \\
(1.380)\end{array}$ & $\begin{array}{c}-1.980 * * \\
(0.780)\end{array}$ \\
\hline Govt. Effectiveness Index & $\begin{array}{c}0.030 \\
(0.145)\end{array}$ & $\begin{array}{c}0.176 \\
(0.816)\end{array}$ & $\begin{array}{c}-0.123 \\
(0.167)\end{array}$ & $\begin{array}{c}-0.062 \\
(0.318)\end{array}$ & $\begin{array}{c}-0.161 \\
(0.131)\end{array}$ & $\begin{array}{c}-0.133 \\
(0.144)\end{array}$ \\
\hline Observations & 455 & 455 & 437 & 437 & 443 & 443 \\
\hline Year Fixed Effects & No & Yes & No & Yes & No & Yes \\
\hline
\end{tabular}

Notes: Dependent variable is share of CFL imports (in logarithm). Country fixed effects included in all estimations. Cluster-robust standard errors in parentheses. ${ }^{*},{ }^{* *}$ and ${ }^{* * *}$ respectively denote significance at $10 \%, 5 \%$ and $1 \%$ levels. Coefficient of constant has not been reproduced.

IV-2SLS results. ${ }^{7}$. Table 3 presents the first-stage results corresponding to these second-stage results presented in Table 2, which are useful to evaluate the factors motivating policymakers to opt for certain policies.

In Table 2, columns one, three and five present the results of considering one policy at a time (information, subsidies and the ban respectively). These specifications include country fixed effects, but do not include time fixed effects. Columns two, four and six in Table 2 present the results including year fixed effects for the same set of policies. While theoretically it may be advisable to include time fixed effects to account for unobserved heterogeneity across different time periods, it is found to be superfluous to include them for these estimations (a joint test of the hypothesis that the coefficients on these effects are zero, leads to a failure to reject the null hypothesis that they are indeed zero). Intuitively, this can be supported by the fact that the dependent variable is a ratio of imports of two similar technologies: if it is indeed the case that there is unobserved variation over time, or trends, both the numerator and the denominator are likely to pick these effects up

7 .Tables 8, 9 and 10 in the Appendix include the OLS, fixed effects and random effects estimations, considering one policy at a time. Fore reasons already mentioned, the IV- 2SLS results are the baseline results of the paper 
identically in the absence of any shocks to one of the two technologies, i.e. it is unlikely that the imports of one type of lighting technology would be influenced by factors varying over time (but common for all countries in the sample) differently from the imports of the other technology. It is more important in this model to control for unobserved heterogeneity across countries, thus the emphasis on the results in columns one, three and five of Table 2.

In column one, the coefficient on information provision is positive, and significant at the five per cent level of significance, suggesting that for this sample, information policies do indeed work in encouraging imports of CFL. The coefficient on the ratio of tariffs on CFL and IB is also significant at the one per cent level of significance, with the expected negative sign (higher the ratio of tariffs on these two technologies, the lower are the shares of CFL imports of countries). The sum of lights variable also has a positive coefficient, suggesting that countries that are more developed are more likely to have higher imports of CFL.

Column three of Table 2 includes the subsidy dummy, which has a positive coefficient and is significant at the five per cent level of significance. The ratio of tariffs variable behaves as before, whereas the coefficient on the sum of night-time lights is positive, and significant at the five per cent level of significance: the higher the number of night time lights, the higher the percentage of CFL imported by the country in a given year. The coefficient on the IB ban dummy in column five is positive and significant at the five per cent level of significance, suggesting that, not surprisingly, the imposition of a ban on IB forces countries to import more CFL. In this specification, the trade agreement indicator is also significant at the five per cent level of significance, with a positive coefficient: if the country enters a trade agreement with one of the top exporters of CFL in a given year, it is more likely to import a larger proportion of CFL in that year.

While there is no specification which includes these policy dummies all together, a comparison of the magnitudes of the coefficients of the policy dummies from these three models suggests that subsidies are the "most effective" policy instrument for this sample, followed by the ban on IB, and lastly information provision. This suggests that in low and middle income countries, cost constraints may be the most limiting barriers towards greater adoption of cleaner technologies by consumers.

Table 3 below presents the results of the first-stage estimations (the first-stage results are only reported for the results corresponding to columns one, three and five of Table 2). In column one, 


\begin{tabular}{lccc}
\hline \hline & $(1)$ & $(2)$ & $(3)$ \\
\hline Information IV & $0.538^{* * *}$ & - & - \\
Subsidies IV & $(0.15)$ & & \\
& - & $0.361^{* * *}$ & - \\
Ban on IB IV & - & $(0.107)$ & - \\
& & & $0.497^{* * *}$ \\
Trade Agreement Indicator & $0.158^{*}$ & 0.0392 & $-0.0938)$ \\
& $(0.0685)$ & $(0.0726)$ & $(0.0441)$ \\
Ratio of Tariffs (in period t-1) & $-0.193^{* *}$ & $-0.150^{*}$ & -0.00704 \\
& $(0.0592)$ & $(0.0642)$ & $(0.0385)$ \\
"Sum-of-Lights" Index & 8.93 & $0.202^{* *}$ & $7.99 *$ \\
& $(5.61)$ & $(0.0646)$ & $(3.95)$ \\
Govt. Effectiveness Index & -0.086 & 0.0323 & 0.0503 \\
& $(0.0893)$ & $(0.0753)$ & $(0.0453)$ \\
\hline Observations & 455 & 437 & 443 \\
Cragg-Donald F-statistic & 24.12 & 11.48 & 28.04 \\
\hline
\end{tabular}

Notes: Dependent variable is the share of CFL imports (in logarithm). Country fixed effects included in all estimations. Cluster-robust standard errors in parentheses. ${ }^{*},{ }^{* *}$ and ${ }^{* * *}$ respectively denote significance at $10 \%, 5 \%$ and $1 \%$ levels. Coefficient of constant has not been reproduced.

the results of the first-stage model, including the information provision dummy as a dependent variable, are provided, while columns two and three include the results for the subsidy dummy and the ban respectively. The results in column one provide evidence to suggest that there is learning between countries in terms of adoption of information provision policies (the coefficient on the presence of information policies in the nearest countries is positive and significant at the one per cent level of significance). While the government effectiveness index is insignificant, we do see evidence that more "developed" economies are more likely to adopt information policies (reflected by the positive coefficient on the sum of lights variable). Additionally, if the country is in a trade agreement with one of the top exporters of CFL in a given year, the country is more likely to implement information provision to encourage consumers to adopt CFL, suggesting that factors facilitating access to a technology are strongly correlated with the decision of policymakers to inform consumers about it.

The choice of a government to provide a subsidy on CFL, (column two, Table 3) suggests that 
the decisions of neighbouring countries to implement subsidies strongly influences policymakers (the instrument has a positive coefficient, significant at the one per cent level of significance), adding strength to the hypothesis that countries learn from each other in implementing policies. Additionally, the more developed a country, the more likely it is to impose a subsidy on CFL (that can be ascertained by the positive coefficient on the sum of lights variable). Also, the higher the ratio of tariffs on the two technologies, the less likely the government is to subsidise this technology (or conversely, if tariffs of CFL with respect to those on IB decrease, the more likely the policymaker is to subsidise them). Column three presents the results of the estimation of the decision of governments to ban IB: again, there is strong evidence to suggest that the decision to ban the import or sale of IB depends positively on whether neighbouring countries have also imposed this policy (the coefficient on the instrument is positive and significant at the one per cent level of significance). Additionally, the ban is more likely to be implemented by countries that are more developed.

The Cragg-Donald F-statistic for identification of weak instruments is found to be 24.12 for the information IV, 11.48 for the subsidy IV and 28.04 for the IV on the ban. These satisfy the rule-of-thumb specified for weak instruments in Staiger and Stock (1997). The instruments are also larger than the critical values suggested by weak instrument-identification tests proposed in Stock and Yogo (2005), at the 15 per cent size for two-stage least squares estimation.

In the results of Table 4 below, the policy dummies are introduced as interaction variable along with the index of government effectiveness to test whether the efficacy with which these policies are implemented could influence the share of CFL adoption. In these specifications, the main effect is the policy dummy variable, and there is an interaction term between the policy dummy and the government effectiveness index. The interpretation of the coefficient on the main effect thus represents the marginal effect of the policy, when the policy implementation is ineffective, and the coefficient on the interaction term represents the marginal effect of the policy when it is effective. The IV-2SLS methodology is not adopted for these estimations, because of the concerns with using multiple endogenous variables, which complicates interpretation of the estimates.

Column one of Table 4 presents the results of the estimations for the information provision policy. The effect of the information policy in the case of ineffective governments is to increase the share of CFL imports by 20.4 per cent, whereas for effective governments, the effect of the policy is 
Table 4: Fixed Effects Estimations on the Role of Government Effectiveness in Policy Enforcement

\begin{tabular}{|c|c|c|c|}
\hline Variables & $\begin{array}{c}(1) \\
\text { Information }\end{array}$ & $\begin{array}{c}(2) \\
\text { Subsidies }\end{array}$ & $\begin{array}{l}\text { (3) } \\
\text { Ban }\end{array}$ \\
\hline Information & $\begin{array}{c}0.039 \\
(0.118)\end{array}$ & - & - \\
\hline Subsidies & - & $\begin{array}{l}2.481 * * \\
(0.149)\end{array}$ & - \\
\hline Ban on IB & - & - & $\begin{array}{l}0.198 * * \\
(0.097)\end{array}$ \\
\hline Information*Govt. effectiveness Index & $\begin{array}{c}-0.565 * * * \\
(0.251)\end{array}$ & - & - \\
\hline Subsidies*Govt. effectiveness Index & - & $\begin{array}{l}-0.017 \\
(0.200)\end{array}$ & - \\
\hline Ban*Govt. effectiveness Index & - & - & $\begin{array}{l}0.280 * * \\
(0.153)\end{array}$ \\
\hline Trade Agreement Indicator & $\begin{array}{c}0.414 * * * \\
(0.172)\end{array}$ & $\begin{array}{l}0.413 * * * \\
(0.166)\end{array}$ & $\begin{array}{c}0.406^{* \cdots *} \\
(0.166)\end{array}$ \\
\hline Ratio of Tariffs (in period $t-1$ ) & $\begin{array}{c}-0.813^{* * *} \\
(0.253)\end{array}$ & $\begin{array}{c}-0.814 * * * \\
(0.245)\end{array}$ & $\begin{array}{c}-0.821^{* * *} \\
(0.239)\end{array}$ \\
\hline "Sum-of-Lights" Index & $\begin{array}{l}-4.870 \\
(6.010)\end{array}$ & $\begin{array}{l}-3.850 \\
(6.940)\end{array}$ & $\begin{array}{l}-5.760 \\
(6.640)\end{array}$ \\
\hline Govt. Effectiveness Index & $\begin{array}{c}0.231 \\
(0.189)\end{array}$ & $\begin{array}{c}-0.058 \\
(0.151)\end{array}$ & $\begin{array}{c}-0.121 \\
(0.119)\end{array}$ \\
\hline Observations & 480 & 480 & 480 \\
\hline
\end{tabular}

Notes: Dependent variable is the share of CFL imports (in logarithm). Country fixed effects included in all estimations. Cluster-robust standard errors in parentheses. ${ }^{*},{ }^{* *}$ and ${ }^{* * *}$ respectively denote significance at $10 \%, 5 \%$ and $1 \%$ levels. Coefficient of constant has not been reproduced.

to reduce the share by 56.5 per cent. The likely reason for this result is that the response to more effective governments providing information to consumers may be an increase in the domestic production capacities of these lamps. While the coefficients on both the subsidy dummy and the interaction term of this variable with the government effectiveness indicator are insignificant in column two, in column three we see that the coefficient on the ban is significant and positive, even when the government is ineffective in enforcing policies (which is represented by the main effect). In the case of an effective government, the marginal effect becomes stronger (an imposition of the ban by an effective government is likely to increase the share of CFL adoption by 28 per cent, versus 20 per cent if the government is not effective).

In order to test for complementarities between policies, three models were estimated. In each model, two main effects (policy dummies) were included, along with their interaction term, the results of which are presented in Table 5 below. The IV-2SLS methodology is not very tractable if there are multiple endogenous instruments (and especially if the instruments are strongly corre- 
Table 5: Fixed Effects Estimations on Complementarities

\begin{tabular}{lccc}
\hline \hline & $(1)$ & $(2)$ & $(3)$ \\
Dependent Variable & \%Share of CFL Imports & \%Share of CFL Imports & \%Share of CFL Imports \\
\hline Information & 0.095 & 0.05 & - \\
Subsidies & $(0.15)$ & $(0.16)$ & 0.31 \\
& -0.014 & - & $(13.05)$ \\
Ban on IB & $(0.13)$ & 0.15 & $(0.11)$ \\
& - & $(0.11)$ & - \\
Information*Subsidies & -0.008 & - & - \\
Information*Ban on IB & $(0.13)$ & $0.13^{* *}$ & -0.25 \\
Subsidies*Ban on IB & - & $(0.09)$ & $(0.19)$ \\
& - & - & $0.45^{* * *}$ \\
Trade Agreement Indicator & $0.43^{* * *}$ & $0.44^{* * *}$ & $(0.16)$ \\
Ratio of tariffs (in period t-1) & $(0.16)$ & $(0.17)$ & $-0.75^{* * *}$ \\
Govt. Effectiveness Index & $-0.74^{* * *}$ & $-0.74 * * *$ & $(0.23)$ \\
"Sum-of-Lights" Index & $(0.24)$ & $(0.24)$ & -0.11 \\
& -0.08 & -0.11 & $(0.11)$ \\
\end{tabular}

Notes: All estimations use 480 observations. Country fixed effects included in all estimations. Cluster-robust standard errors in parentheses. ${ }^{*},{ }^{* *}$ and ${ }^{* * *}$ respectively denote significance at $10 \%, 5 \%$ and $1 \%$ levels. Coefficient of constant has not been reproduced.

lated, as shown in the correlation matrix in Table 7). Thus, a fixed effects estimation methodology is adopted to obtain these results, despite endogeneity concerns.

There is no conclusive evidence to suggest that information and subsidies are complementary, as the results in column one of Table 5 suggest. Both the main effects and the interaction term are insignificant. In column two, the estimation tests for the complementarity between information provision and the ban on IB. Results suggest that in the absence of information, the variable for the ban is insignificant, whereas if information is provided to consumers, the ban becomes effective in increasing CFL imports (the interaction is significant at the five per cent level of significance). Lastly, column three of this table tests for possible complementarity between the ban on IB and subsidies on CFL. While the ban on IB has a strong positive (and significant) effect on CFL imports, the presence of a subsidy does nothing to augment its effectiveness (the interaction term is insignificant). These results suggest that the only possible policy combination, where one policy is more effective in the presence of another, is information and the ban on IB. 


\section{Policy implications}

The paper's preliminary results offer interesting policy implications. The empirical results indicate the importance of all three policy options, such as information provision schemes, subsidies and the IB ban, in encouraging CFL adoption in low and middle-income countries. In particular, price hurdles appear to be the binding constraint in low and middle-income countries (this can be confirmed by the sizes of the coefficients derived on the policy dummies in section results).

The effectiveness with which policies can be implemented (i.e. the credibility of the government providing the information, and the strength with which the ban is enforced) and on what the scale (the size of the subsidy, for example) are hypothesised to be factors which determine the choice of policy. The empirical model finds that the adoption of subsidies by governments depends positively on the level of income of the country, while the adoption of the ban on IB as an instrument depends on the effectiveness with which the government can implement policies.

However, the empirical model does not find evidence to suggest that information provision is adopted by governments that are more effective. This may be attributed to the lack of a better indicator of provision of "credible" information to consumers. Given that the onus for implementing labelling schemes falls on firms, the role of the policymaker in ensuring that accurate information is provided to consumers is difficult to measure using the data that is available.

The results also conclude that countries learn from the experiences of their neighbours in deciding whether to implement a policy. It also finds that effectiveness in policy implementation plays a critical role in determining whether a policy has an effect on diffusion, especially in the case of a ban.

Regarding possible complementarities between policies, the results of this paper find that for this sample of countries, the ban is only effective if information provision is also adopted. This may stem from the poor enforcement of the ban in these countries. However, subsidies are not a prerequisite for the ban to be effective. This suggests that governments that are endowed with more resources for policy implementation may be better off using them to implement subsidies (which are highly effective). Countries that are more effective at policy implementation could benefit from implementing a ban on older technologies, whilst providing information to the consumers about the new technology. Conversely, governments that are not well-endowed and cannot implement policies effectively, will not be able to ensure that consumers switch to cleaner technologies. 
It is interesting to contrast the results of this paper with those provided by the literature on developed countries. Coad et al. (2009), for instance, provide policy implications of sequencing policies to encourage consumers to buy green cars, using Swiss survey data. They find that information provision policies (such as the energy label for cars) may be more effective when imposed at the beginning of the diffusion process in encouraging intrinsically green consumers, concerned about the environmental implications of their actions, to adopt green cars. However, financial incentive schemes (such as subsidies or fines) and regulatory "sticks" may be more effective later on, to provide incentives for less environmentally-motivated consumers who need monetary incentives to adopt a technology. Allcott and Taubinsky (2015) find that among US consumers of clean light bulbs: information provision is the first-best policy in terms of welfare, the second is a subsidy, while a ban is unlikely to lead to an improvement in consumer welfare.

The paper also finds a positive role for trade policy in encouraging the adoption of clean technologies. For instance, trade agreements with the top exporters of certain technologies could facilitate technology transfer. Tariffs can also be lowered on clean technology, which is primarily transferred through the channel of trade.

There are some caveats to the results derived in this paper. Firstly, the empirical model proxies the implementation of policies in the sample of countries by dummies, which circumvents the scale of the programs implemented, or any geographical disparities. Additionally, it is also unable to account for any lags between the announcement of the policies and their implementation. This may be particularly relevant in case of the ban on incandescent bulbs, for instance, because there is scant data on the dates of announcements of the incandescent ban for the countries represented in the sample. Mills and Schleich (2014) use German survey data to find that households hoarded incandescent lamps after the announcement of the policy and before the ban was actually implemented. Such effects cannot be tested with the data used in this paper.

\section{Conclusion}

The objective of this paper was to evaluate the effectiveness of different types of policies in influencing the diffusion of clean technologies (such as CFL) to low and middle-income countries, which are not large producers. The main results of this paper are that for consumers who are new 
to a more expensive, yet more energy-efficient technology, information provision, subsidies and a ban on the incumbent technology all ensure greater adoption. However subsidies remain the most effective tool, suggesting that cost-related barriers are the most significant (at least for this particular technology). In addition, the decision of a policymaker to implement policies depends on the experiences of other (similar) countries, on the effectiveness with which these policies can be enforced, and the amount of resources available to the policymaker to implement these policies.

Regarding possible complementarities between policies, governments with more resources available for energy efficiency policies may be better off using them to implement subsidies, at least in the short-run, whereas governments capable of implementing policies efficiently may benefit from banning older technologies, and simultaneously providing information to the consumers about the new technology (since they are found to be complementary policies).

In conclusion, this paper finds that policymakers wishing to encourage consumers in developing countries to adopt a new technology could benefit from taking into account the effectiveness of different instruments, given their resources and policy environment, and learning from the experiences of similar countries. 


\section{Appendix}

Table 6: Countries Included in Data Sample

\begin{tabular}{cccccc}
\hline \hline Albania & Costa Rica & Guatemala & Madagascar & Pakistan & Suriname \\
Argentina & Cote d'Ivoire & Guinea-Bissau & Malawi & Panama & Swaziland \\
Bangladesh & Cuba & Guyana & Malaysia & Peru & Tajikistan \\
Belarus & DRC & Haiti & Mali & Philippines & Togo \\
Belize & Dominica & Honduras & Mauritius & Romania & Tunisia \\
Benin & Dominican Republic & India & Mexico & Rwanda & Turkey \\
Bolivia & Egypt & Iran & Morocco & Saint Lucia & Uganda \\
Brazil & El Salvador & Jamaica & Mozambique & Senegal & Ukraine \\
Bulgaria & Ecuador & Jordan & Namibia & Seychelles & Venezuela \\
Cape Verde & Ethiopia & Kazakhstan & Nepal & South Africa & Vietnam \\
CAR & Gambia & Kenya & Nicaragua & Sri Lanka & Zambia \\
Colombia & Ghana & Lebanon & Nigeria & Sudan & Zimbabwe \\
\hline
\end{tabular}


Figure 1: Policies Implemented By Countries

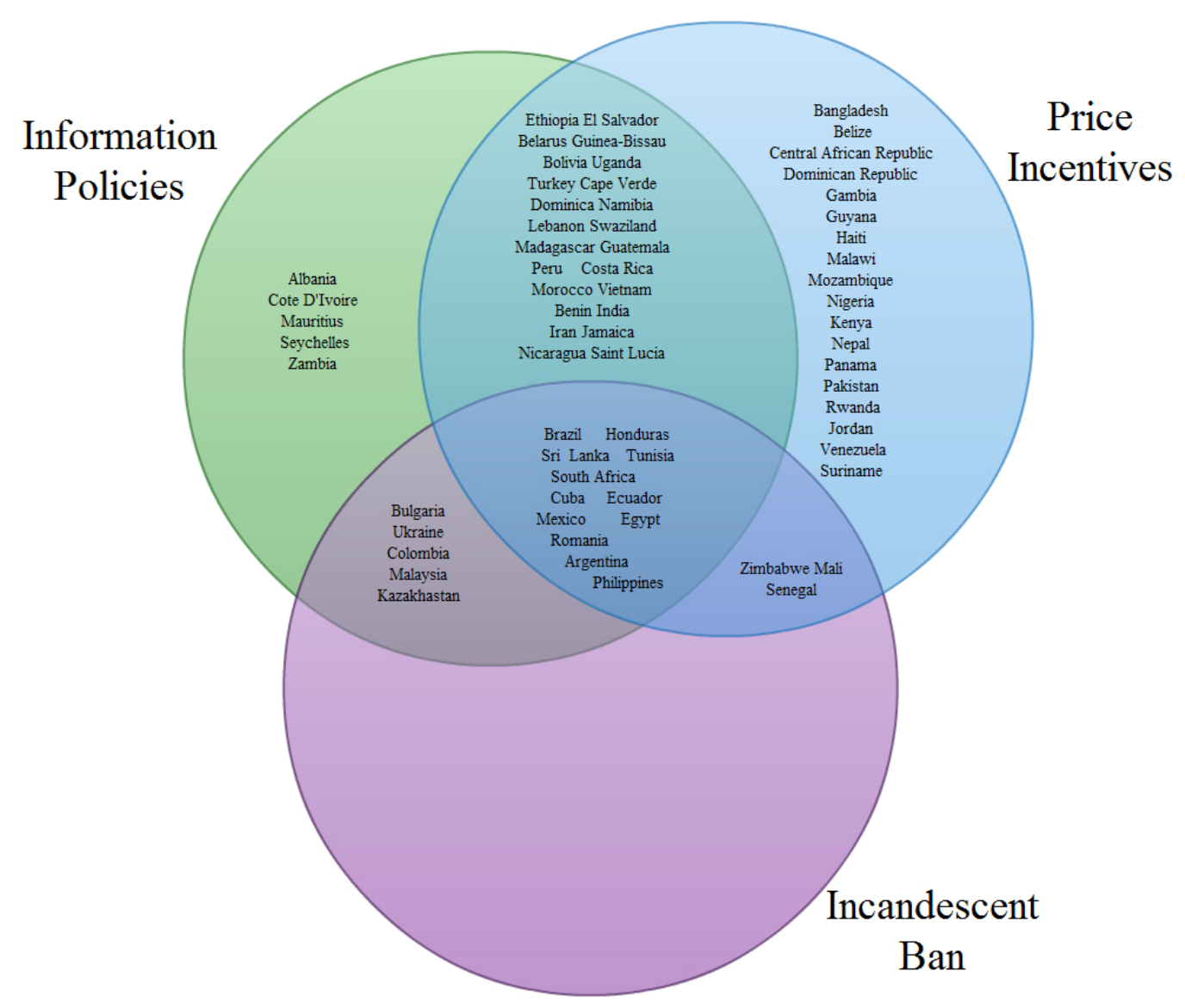


Figure 2: Policy Adoption Rates (averaged across countries)

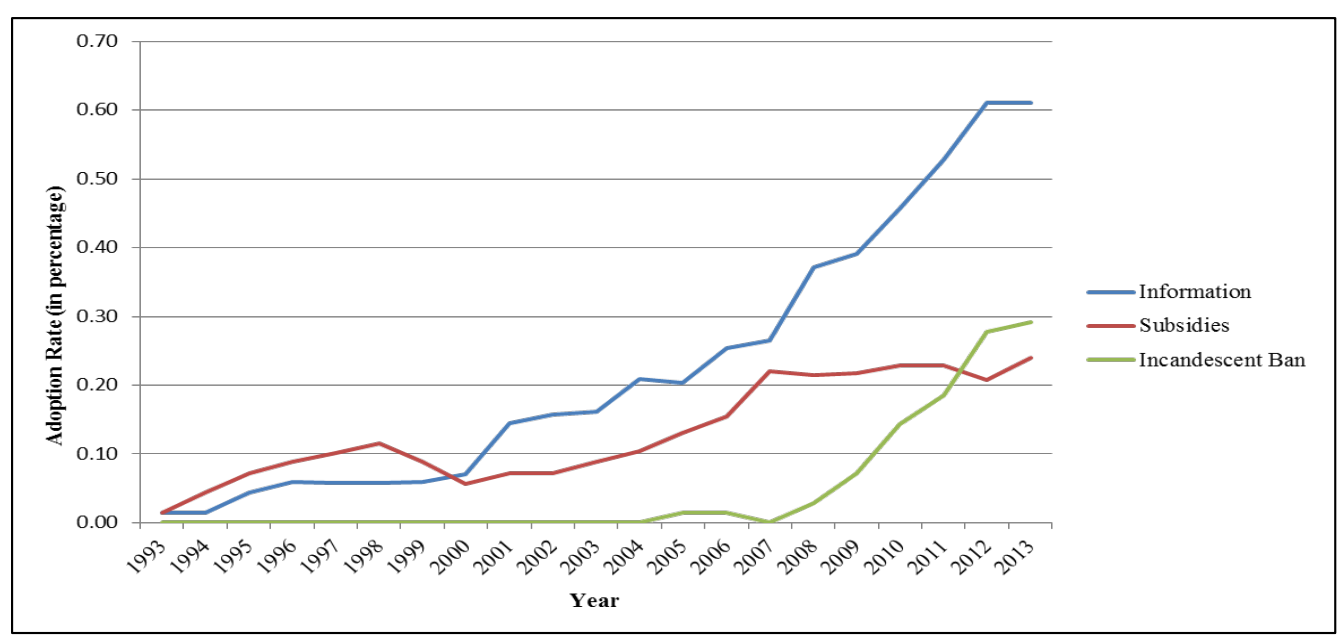


Figure 3: Evolution in Share of CFL Imports

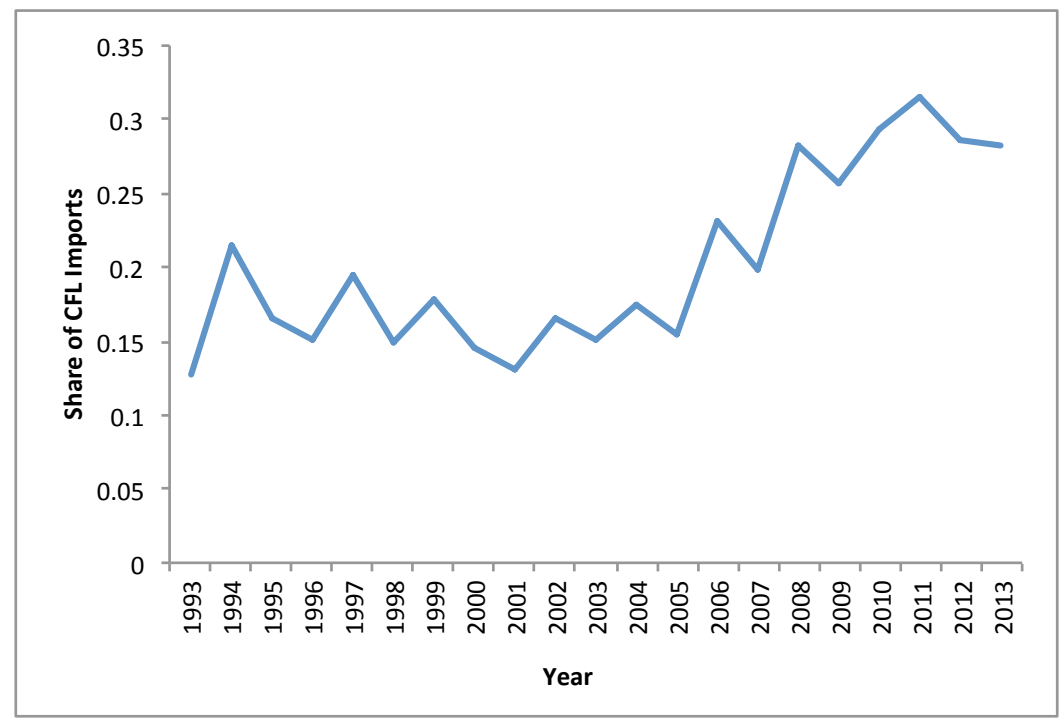


Figure 4: Evolution of Share of CFL Exports

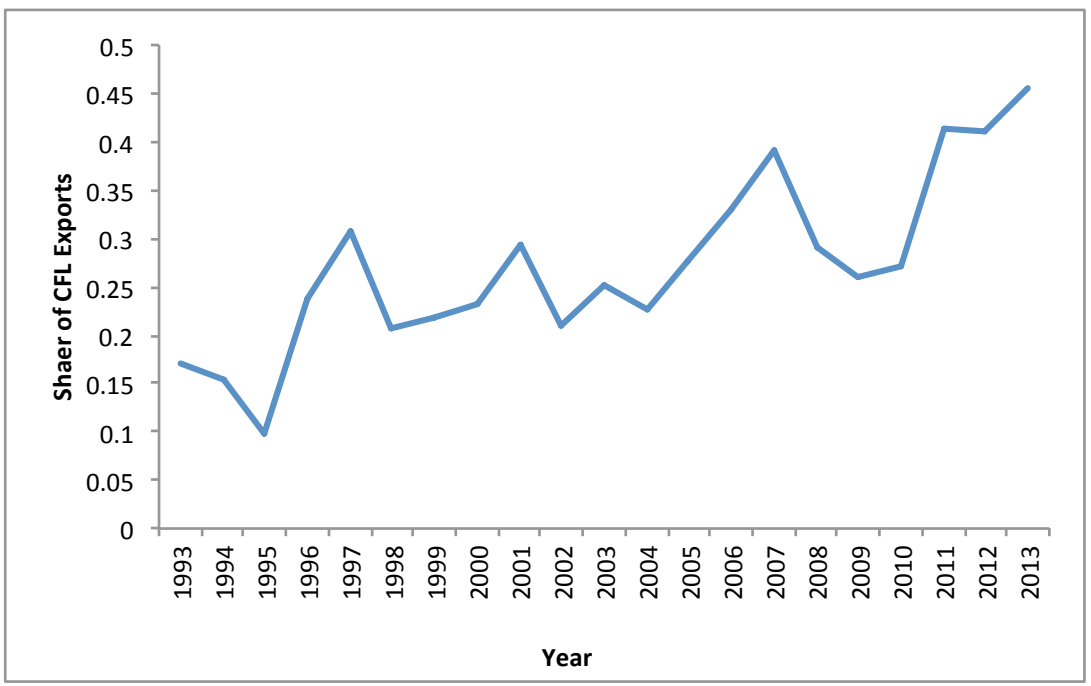




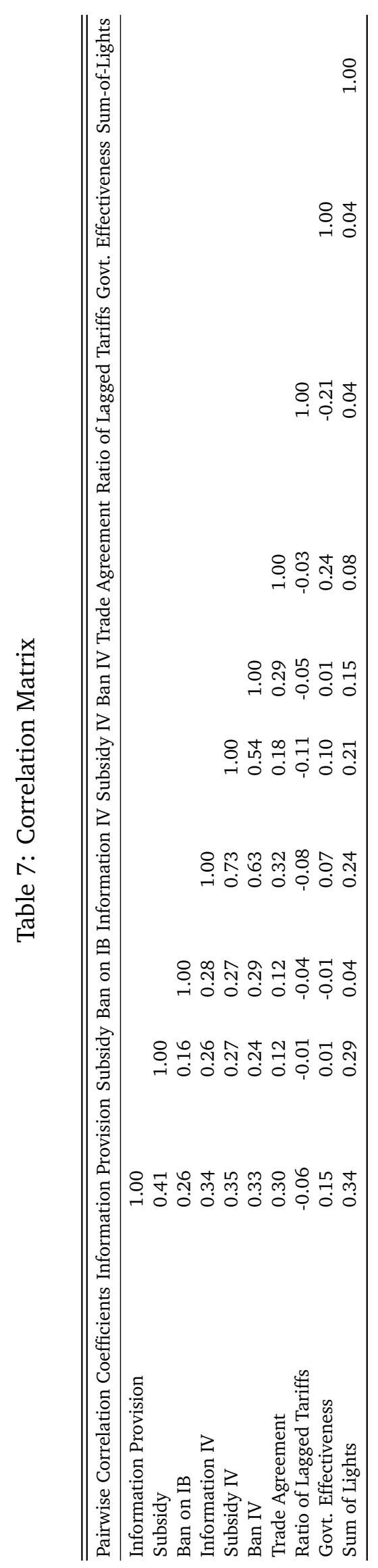


Table 8: Pooled OLS, Fixed Effects and Random Effects: Information Provision

\begin{tabular}{|c|c|c|c|c|}
\hline Dependent Variable & $\begin{array}{c}(1) \\
\text { Pooled OLS } \\
\text { \%Share of CFL Imports }\end{array}$ & $\begin{array}{c}(2) \\
\text { Country FE } \\
\text { \%Share of CFL Imports }\end{array}$ & $\begin{array}{c}\text { (3) } \\
\text { Country and Year FE } \\
\text { \%Share of CFL Imports }\end{array}$ & $\begin{array}{c}(4) \\
\text { RE } \\
\text { \% Share of CFL Imports }\end{array}$ \\
\hline Information (including lags of periods $\mathrm{t}-1, \mathrm{t}-2$ and $\mathrm{t}-3$ ) & $\begin{array}{c}0.466^{* * *} \\
(0.149)\end{array}$ & $\begin{array}{c}0.123 \\
(0.134)\end{array}$ & $\begin{array}{c}-0.189 \\
(0.158)\end{array}$ & $\begin{array}{c}0.156 \\
(0.137)\end{array}$ \\
\hline Trade Agreement Indicator & $\begin{array}{c}0.942^{* * *} \\
(0.125)\end{array}$ & $\begin{array}{l}0.395^{* *} \\
(0.170)\end{array}$ & $\begin{array}{l}0.0693 \\
(0.187)\end{array}$ & $\begin{array}{c}0.425^{* * *} \\
(0.161)\end{array}$ \\
\hline Ratio of Tariffs (in period t-1) & $\begin{array}{l}-0.234 \\
(0.153)\end{array}$ & $\begin{array}{c}-0.792^{* * *} \\
(0.245)\end{array}$ & $\begin{array}{c}-0.676^{* * *} \\
(0.267)\end{array}$ & $\begin{array}{c}-0.725^{* * * *} \\
(0.233)\end{array}$ \\
\hline Government Effectiveness Indicator & $\begin{array}{c}-0.508^{* * *} \\
(0.154)\end{array}$ & $\begin{array}{l}-0.0668 \\
(0.107)\end{array}$ & $\begin{array}{c}-0.113 \\
(0.0961)\end{array}$ & $\begin{array}{l}-0.0901 \\
(0.108)\end{array}$ \\
\hline Sum of Lights & $\begin{array}{l}2.92^{* * *} \\
(0.396)\end{array}$ & $\begin{array}{l}-4.46 \\
(6.37)\end{array}$ & $\begin{array}{l}-2.21^{*} \\
(1.32)\end{array}$ & $\begin{array}{l}2.04^{* * *} \\
(0.678)\end{array}$ \\
\hline
\end{tabular}

Notes: All estimations use 480 observations. Cluster-robust standard errors in parentheses. ${ }^{*},{ }^{* *}$ and ${ }^{* * *}$ respectively denote significance at $10 \%, 5 \%$ and $1 \%$ levels. Coefficient of constant has not been reproduced.

Table 9: Pooled OLS, Fixed Effects and Random Effects: Subsidies

\begin{tabular}{|c|c|c|c|c|}
\hline Dependent Variable & $\begin{array}{c}\text { (1) } \\
\text { Pooled OLS } \\
\text { \%Share of CFL Imports }\end{array}$ & $\begin{array}{c}\text { (2) } \\
\text { Country FE } \\
\text { \%Share of CFL Imports }\end{array}$ & $\begin{array}{c}\text { (3) } \\
\text { Country and Year FE } \\
\text { \%Share of CFL Imports }\end{array}$ & $\begin{array}{c}\text { (4) } \\
\text { RE } \\
\text { \% Share of CFL Imports }\end{array}$ \\
\hline Subsidies (including lags of periods $\mathrm{t}-1, \mathrm{t}-2$ and $\mathrm{t}-3$ ) & $\begin{array}{l}0.0788 \\
(0.145)\end{array}$ & $\begin{array}{l}-0.0171 \\
(0.109)\end{array}$ & $\begin{array}{l}-0.214^{*} \\
(0.108)\end{array}$ & $\begin{array}{l}-0.0114 \\
(0.109)\end{array}$ \\
\hline Trade Agreement Indicator & $\begin{array}{c}0.989^{* * *} \\
(0.126)\end{array}$ & $\begin{array}{l}0.419 * * \\
(0.163)\end{array}$ & $\begin{array}{l}0.0430 \\
(0.189)\end{array}$ & $\begin{array}{c}0.452^{* * *} \\
(0.153)\end{array}$ \\
\hline Ratio of Tariffs (in period $\mathrm{t}-1$ ) & $\begin{array}{l}-0.279^{*} \\
(0.156)\end{array}$ & $\begin{array}{c}-0.823^{* * * *} \\
(0.241)\end{array}$ & $\begin{array}{c}-0.650 * * \\
(0.266)\end{array}$ & $\begin{array}{c}-0.762^{* * *} \\
(0.228)\end{array}$ \\
\hline Govt. Effectiveness Index & $\begin{array}{c}-0.459 * * * \\
(0.157)\end{array}$ & $\begin{array}{c}-0.0642 \\
(0.107)\end{array}$ & $\begin{array}{c}-0.114 \\
(0.0961)\end{array}$ & $\begin{array}{l}-0.0851 \\
(0.107)\end{array}$ \\
\hline "Sum-of-Lights" Index & $\begin{array}{c}3.36^{* * * *} \\
(0.40)\end{array}$ & $\begin{array}{l}-2.69 \\
(5.9)\end{array}$ & $\begin{array}{l}-2.34^{* *} \\
(0.116)\end{array}$ & $\begin{array}{c}2.217 * * * \\
(0.676)\end{array}$ \\
\hline
\end{tabular}

Notes: All estimations use 480 observations. Cluster-robust standard errors in parentheses. ${ }^{*},{ }^{* *}$ and ${ }^{* * *}$ respectively denote significance at $10 \%, 5 \%$ and $1 \%$ levels. Coefficient of constant has not been reproduced.

Table 10: Pooled OLS, Fixed Effects and Random Effects: Ban on IB

\begin{tabular}{|c|c|c|c|c|}
\hline Dependent Variable & $\begin{array}{c}\text { (1) } \\
\text { Pooled OLS } \\
\text { \%Share of CFL Imports }\end{array}$ & $\begin{array}{c}(2) \\
\text { Country FE } \\
\text { \%Share of CFL Imports }\end{array}$ & $\begin{array}{c}\text { (3) } \\
\text { Country and Year FE } \\
\text { \%Share of CFL Imports }\end{array}$ & $\begin{array}{c}\text { (4) } \\
\text { RE } \\
\text { \% Share of CFL Imports }\end{array}$ \\
\hline Ban on IB (including lags of periods $t-1, t-2$ and $t-3$ ) & $\begin{array}{c}0.885^{* * *} \\
(0.285)\end{array}$ & $\begin{array}{c}0.138 \\
(0.118)\end{array}$ & $\begin{array}{c}-0.158 \\
(0.194)\end{array}$ & $\begin{array}{c}0.161 \\
(0.121)\end{array}$ \\
\hline Trade Agreement Indicator & $\begin{array}{c}1.015^{* * *} \\
(0.125)\end{array}$ & $\begin{array}{l}0.415^{* *} \\
(0.165)\end{array}$ & $\begin{array}{l}0.0768 \\
(0.195)\end{array}$ & $\begin{array}{c}0.452^{* * *} \\
(0.155)\end{array}$ \\
\hline Ratio of Tariffs (in period t- 1 ) & $\begin{array}{l}-0.270 * \\
(0.152)\end{array}$ & $\begin{array}{c}-0.818^{* * * *} \\
(0.238)\end{array}$ & $\begin{array}{c}-0.659^{* * *} \\
(0.268)\end{array}$ & $\begin{array}{c}-0.753^{* * *} \\
(0.225)\end{array}$ \\
\hline Govt. Effectiveness Index & $\begin{array}{c}-0.452^{* * *} \\
(0.153)\end{array}$ & $\begin{array}{l}-0.0751 \\
(0.103)\end{array}$ & $\begin{array}{c}-0.107 \\
(0.0987)\end{array}$ & $\begin{array}{l}-0.0973 \\
(0.106)\end{array}$ \\
\hline "Sum-of-Lights" Index & $\begin{array}{c}3.45^{* * *} \\
(0.37)\end{array}$ & $\begin{array}{l}-3.43 \\
(0.61)\end{array}$ & $\begin{array}{c}-2.17^{*} \\
(1.3)\end{array}$ & $\begin{array}{c}2.25^{* * * *} \\
(0.66)\end{array}$ \\
\hline
\end{tabular}

Notes: All estimations use 480 observations. Cluster-robust standard errors in parentheses. ${ }^{*},{ }^{* *}$ and ${ }^{* * *}$ respectively denote significance at $10 \%, 5 \%$ and $1 \%$ levels. Coefficient of constant has not been reproduced. 


\section{References}

ALA, "American Lighting Association: Types of Light Sources and Light Bulbs," URL: https: / / www .americanlightingassoc.com/Lighting-Fundamentals/ Light-Sources-Light-Bulbs.aspx (AccessedJune2014).

Allcott, Hunt and Dmitry Taubinsky (2015) "Evaluating Behaviorally Motivated Policy: Experimental Evidence from the Lightbulb Market," American Economic Review, Vol. 105, pp. 2501-38.

Anderson, Gordon J (1987) "Prediction tests in limited dependent variable models," Journal of econometrics, Vol. 34, pp. 253-261.

Angrist, Joshua D and Jörn-Steffen Pischke (2008) Mostly harmless econometrics: An empiricist's companion: Princeton university press.

Ashraf, Nava, B Kelsey Jack, and Emir Kamenica (2013) "Information and subsidies: Complements or substitutes?” Journal of Economic Behavior and Organization, Vol. 88, pp. 133-139.

Bosetti, Valentina and Elena Verdolini (2013) "Clean and Dirty International Technology Diffusion."

Caselli, Francesco and Wilbur John Coleman (2001) "Cross-Country Technology Diffusion: The Case of Computers," American Economic Review, Vol. 91, pp. 328-335.

Coad, Alex, Peter de Haan, and Julia Sophie Woersdorfer (2009) "Consumer support for environmental policies: An application to purchases of green cars," Ecological Economics, Vol. 68, pp. $2078-2086$.

Comin, Diego A, Mikhail Dmitriev, and Esteban Rossi-Hansberg (2012) "The spatial diffusion of technology,"Technical report, National Bureau of Economic Research.

Comin, Diego and Bart Hobijn (2004) "Cross-country technology adoption: making the theories face the facts," Journal of monetary Economics, Vol. 51, pp. 39-83.

De Sousa, Jose (2012) "The currency union effect on trade is decreasing over time," Economics Letters, Vol. 117, pp. 917-920.

DeGroot, Morris (1970) "Optimal Statistical Decisions."

Ebeke, Mr Christian and Mr Constant Lonkeng Ngouana (2015) Energy Subsidies and Public Social Spending: Theory and Evidence, No. 15-101: International Monetary Fund.

Geroski, Paul A (2000) "Models of technology diffusion," Research policy, Vol. 29, pp. 603-625.

Griliches, Zvi (1957) "Hybrid corn: An exploration in the economics of technological change," Econometrica, Journal of the Econometric Society, pp. 501-522.

Guasch, J Luis, Jean-Jacques Laffont, and Stephane Straub (2003) Renegotiation of concession contracts in Latin America, Vol. 3011: World Bank Publications.

Jaffe, Adam B and Robert N Stavins (1994) "The energy paradox and the diffusion of conservation technology," Resource and Energy Economics, Vol. 16, pp. 91-122.

Johnstone, Nick, Ivan Haščič, and David Popp (2010) "Renewable energy policies and technological innovation: evidence based on patent counts," Environmental and resource economics, Vol. 45, pp. 133-155. 
Keen, Michael and Ben Lockwood (2010) "The value added tax: Its causes and consequences," Journal of Development Economics, Vol. 92, pp. 138-151.

Lefèvre, Nicolas, P T'Serclaes, and Paul Waide (2006) "Barriers to technology diffusion: the case of compact fluorescent lamps," Joint OECD and IEA Paper, Paris, pp. 1-35.

Mansfield, Edwin (1961) "Technical change and the rate of imitation," Econometrica: Journal of the Econometric Society, pp. 741-766.

(1968) "Industrial research and technological innovation; an econometric analysis."

Mayer, Thierry and Soledad Zignago (2011) "Notes on CEPII's distances measures: The GeoDist database."

Mills, Bradford F and Joachim Schleich (2010) "Why don't households see the light?: Explaining the diffusion of compact fluorescent lamps," Resource and Energy Economics, Vol. 32, pp. 363378.

Mills, Bradford and Joachim Schleich (2014) "Household transitions to energy efficient lighting," Energy Economics, Vol. 46, pp. 151-160.

Newell, Richard G. and Juha Siikamaki (2014) "Nudging Energy Efficiency Behavior: The Role of Information Labels," Journal of the Association of Environmental and Resource Economists, Vol. 1, pp. 555-598.

NOAA (2014) “Version 4 DMSP-OLS Nighttime Lights Time Series,” Accessed April 2014.

Papageorgiou, Chris, Andreas Savvides, and Marios Zachariadis (2007) "International medical technology diffusion," Journal of International Economics, Vol. 72, pp. 409-427.

Reppelin-Hill, Valérie (1999) "Trade and environment: An empirical analysis of the technology effect in the steel industry," Journal of Environmental Economics and Management, Vol. 38, pp. $283-301$.

Requate, Till and Wolfram Unold (2003) "Environmental policy incentives to adopt advanced abatement technology:: Will the true ranking please stand up?" European Economic Review, Vol. 47, pp. 125-146.

Staiger, Douglas O and James H Stock (1997) "Instrumental variables regression with weak instruments," Econometrica, Journal of the Econometric Society, Vol. 65, pp. 557-586.

Stock, James H and Motohiro Yogo (2005) "Testing for weak instruments in linear IV regression," Identification and inference for econometric models: Essays in honor of Thomas Rothenberg.

Teisl, Mario F, Brian Roe, and Robert L Hicks (2002) "Can eco-labels tune a market? Evidence from dolphin-safe labeling," Journal of Environmental Economics and Management, Vol. 43, pp. 339-359.

UN (2014) “UN Comtrade International Trade Statistics Database," Accessed June 2014.

UNEP (2014) “En.lighten Initiative Country Data,” Accessed June 2014.

Ward, David O, Christopher D Clark, Kimberly L Jensen, Steven T Yen, and Clifford S Russell (2011) "Factors influencing willingness-to-pay for the ENERGY STAR® label," Energy Policy, Vol. 39, pp. 1450-1458. 
WB (2012) "World Development Indicators 2012," Accessed June 2014, URL: http:// data. worldbank.org/data-catalog/world-development-indicators.

(2014) "World Integrated Trade Solution (WITS) Database," Accessed June 2014.

Young, H Peyton (2009) "Innovation diffusion in heterogeneous populations: Contagion, social influence, and social learning," The American economic review, Vol. 99, pp. 1899-1924. 